\title{
Food Synergy: \\ The Key to Balancing the Nutrition Research Effort
}

\author{
David R. Jacobs, Jr., PhD, ${ }^{1}$ \\ Linda C. Tapsell, $\mathrm{PhD},{ }^{2}$ \\ Norman J. Temple, $\mathrm{PhD}^{3}$
}

\begin{abstract}
Mediterranean-type diet patterns are consistently associated with reduced risk for cardiovascular disease, diabetes, and cancer in the general population. In contrast, several randomized controlled trials (RCTs) focusing on nutrient supplements have shown no or adverse long-term effects on long-term chronic disease. Food in its natural form is a nonrandom mixture of numerous molecules, orchestrated evolutionarily to maintain the life of the organism being eaten. Food synergy assumes that the biologically determined combination of nutrients and other bioactive substances found in food plays a concerted role in influencing health. Coupled with reduced risk in the Mediterranean-type diet pattern, food synergy implies that the concerted action of nutrients and other bioactive substances in fruit, vegetables, whole grain cereals, nuts, and legumes is beneficial for health. The assumption that single molecules work in isolation as they work in food violates the food synergy concept of concerted action and often leads to a partial picture. Public health nutrition strategies that focus on single nutrients have led to a flourishing diet supplement industry and advice to the public to eat low-fat diets. The latter is questionable in two respects: not all fats are equal, and industry efforts to comply spun-off products high in refined carbohydrates. It is time to rethink the research paradigm concerning diet and health. Reductionist research, though valuable, focuses on partial pathways, rather than the whole system integrating a lifetime of food intake with the long-term health of intact humans. Epidemiology provides this information, but is subject to residual confounding. RCTs are useful, but RCTs of food differ fundamentally from RCTs of drugs; for example, in terms of blinding,
\end{abstract}

\footnotetext{
${ }^{1}$ University of Minnesota, School of Public Health Division of Epidemiology and Community Health, Minneapolis, USA; also affiliated with the University of Oslo, School of Medicine, Department of Nutrition, Norway

${ }^{2}$ The Smart Foods Centre, University of Wollongong, Wollongong, Australia

${ }^{3}$ Centre for Science, Athabasca University, Alberta, Canada
}

Corresponding Author Contact Information: David R. Jacobs, Jr. at jacob004@umn.edu or jacobs@epi.umn.edu; Mayo Professor of Public Health, Division of Epidemiology and Community Health, School of Public Health, University of Minnesota, 1300 S 2nd St, Suite 300, Minneapolis MN 55454, USA. 
long-term adherence, and specificity of the reference treatment. All research inferences are most secure when based on convergent evidence from multiple research approaches. A balanced approach is therefore needed in nutrition research.

Key words: Food synergy, dietary patterns, epidemiology, research implications, reductionism

Recommended Citation: Jacobs DR Jr, Tapsell LC, Temple NJ. Food synergy: the key to balancing the nutrition research effort. Public Health Reviews. 2012;33:50729.

\section{INTRODUCTION}

This paper contrasts strategies for conducting nutrition research that investigate the relationship between diet and disease. This research is the basis for public policy recommendations, notably advice about diet. Historically, nutrition research has focused on single substances, whether macronutrients, micronutrients, or the many other bioactive substances present in food. A more recent strategy focuses on food synergy, which is based on the assumption that in most cases the many substances in food have additive or more than additive effects on health. ${ }^{1-5}$

The position we take in this paper is that too great a focus on single nutrients or other bioactive substances will not significantly advance public health dietary advice, unless deficiency diseases are present. As a strategy for advancing nutrition science that informs this advice, a focus on single nutrients is unlikely to succeed because in the large majority of cases this research does not model the complex effects of food consumption on human biology. Even where simple additive effects of single substances may emerge and be important, it is very difficult to translate this knowledge to that relating to the consumption of whole foods and whole diets. A strategic approach that will prove more fruitful and better inform public health dietary advice is to focus on food and dietary patterns, within the concept we call food synergy.

The aim of this paper is to defend this position. First, the concepts of nutrient deficiency and food synergy are presented along with a brief summary of exemplary research that addresses the relationship between dietary patterns and disease. The concept of food synergy is then applied to the research context, with considerations for research designs, such as observational studies, randomized controlled trials (RCTs), or experiments in the basic sciences, with the assertion that correct inferences are most likely to be made based on convergent evidence from multiple perspectives. The conclusion focuses on lessons for research design which integrates the preceding appraisal. 


\section{NUTRIENT DEFICIENCY DISEASES: AN INFORMATIVE BUT LIMITED REFERENCE POINT}

For several decades, roughly from the 1920s to the 1950s, nutrition science achieved great success in identifying the various vitamins and minerals in food and discovering their mode of action. This was made possible by clearly defining actions through the disciplines of biochemistry and physiology. In turn, a nutrient deficiency could be linked to specific symptoms. The deficiency disease could be prevented (and often reversed) by giving that nutrient in an isolated (pure) form.

It has been many years since any new essential nutrient has been discovered that explains the cause of a deficiency disease. However, the concept is still very much alive, though in a modified form. In recent years studies of single substances contained in food have led to promising advances in several areas of health. A noteworthy example of this is vitamin D. Much evidence suggests that suboptimal levels are widespread in many populations and that this significantly increases the risk for several disorders, including possibly cancer. ${ }^{6}$ However, not all observational epidemiologic studies show benefit from supplemental vitamin D. ${ }^{7}$ It may be that jumping into supplementation is not the correct or only response to the observation of increased risk associated with low vitamin D levels. A rational response would ask what else could the associations mean and whether there is a broader sphere of action that might need to be considered?

There are many other bioactive substances in food apart from micronutrients. It must be remembered, however, that our ability to discern whether food components are beneficial or harmful is likely to be related to the balance in the amount consumed. Prominent examples are as follows:

- The great majority of the population has an excessive intake of sodium and this is closely associated with hypertension ${ }^{8.9}$ and cardiovascular disease (CVD) ${ }^{9,10}$ This may also be a significant factor in stomach cancer. ${ }^{11}$

- Consumption of significant amounts of trans fatty acids, which are primarily the result of hydrogenation of fatty acids to increase hardness and which until recently were present in margarines and many baked products, increase the risk of coronary heart disease (CHD). ${ }^{12,13}$

- The harmful effects of a high intake of alcohol are well known. In sharp contrast to this, epidemiological evidence that has appeared over the past two decades shows that a moderate consumption of alcohol lowers the risk of $\mathrm{CHD}^{14}$ and possibly several other conditions. ${ }^{15}$ The active ingredient is alcohol itself, not the other substances commonly found in alcoholic beverages. 
The above examples show that nutrition science does achieve important progress in select areas by studying the relationship between single substances and health or disease. But a clear pattern has emerged showing that such cases are in the minority. Later in this paper we cite epidemiological studies that report that intake of particular nutrients manifests a "protective" association with various diseases backed by basic science findings, but when these nutrients were given as supplements in RCTs, no evidence was seen of a decrease in disease occurrence. A new dimension to researching nutrition is required.

\section{FOOD SYNERGY: A CONCEPTUAL FRAMEWORK FOR ADDRES- SING THE GAPS}

The challenge for nutrition scientists is to understand and explain the many associations between diet and risk of disease, both for a fundamental understanding of biologic pathways and for providing dietary advice. We argue here that this may be best accomplished by viewing food as a whole integrated system, and not merely as a collection of individual nutrients and other bioactive substances. Food is in the first instance a complex, nonrandom collection of molecules orchestrated evolutionarily for the life of the organism being eaten. The relationship between the study of food and the study of nutrients needs to be better articulated for the development of public health policy. From a public health perspective, the study of foods (and their combination in dietary patterns) is central because food is what people eat and such study is directly applicable to dietary advice. Simply put, the concept of food synergy has provided a better explanation for chronic nutrition-related diseases, such as obesity, diabetes, and CVD, and how best to prevent and treat them. The following examples of research on whole diets attest to this position.

\section{Example \#1: The Mediterranean Diet}

A highly informative systematic review based on findings from cohort studies $^{16}$ found of all the nutritional associations with risk of CHD (nutrients, foods, dietary patterns), either positive or negative, the strongest one was for the Mediterranean diet patterns. How can this finding be best explained?

While the diet shows much variation between countries around the Mediterranean, the dietary pattern typically includes a generous intake of fruit, vegetables, whole-grain cereals, legumes, nuts, and includes fish and 
olive oil. Meat, especially red meat, is usually eaten in low amounts. The Mediterranean diet therefore has a complex nutritional composition. Although it is rich in phytochemicals but low in saturated fat, heme iron, and many other substances found in meat, it is difficult to know to what extent these substances have an impact on the health success of this diet pattern. It seems highly likely that many dietary components and multiple pathways are responsible. This diet-disease association provides strong support for the food synergy concept.

\section{Example \#2: The Alternate Healthy Eating Index}

Similar findings have come from studies of another dietary pattern, the Alternate Healthy Eating Index. ${ }^{17}$ Middle-aged women following this dietary pattern have a much reduced risk of death from CVD, from cancer, and from all causes combined. ${ }^{18}$

\section{Example \#3: The A Priori Diet Quality Score}

This is a novel index based on foods. ${ }^{19}$ It was constructed by experts in nutrition and nutritional epidemiology as the sum of ranks of foods groups judged to have a beneficial effect on health. It was related to several aspects of improved health including reduced risk of myocardial infarction and incident diabetes. ${ }^{19-22}$

\section{Example \#4: The Western Dietary Pattern}

In contrast to the above three examples the "Western" dietary pattern is unhealthy. This diet is high in red meat, processed meat, refined cereals, French fries, and desserts, and correspondingly low in phytochemical-rich plant foods. A report from the Nurses' Health Study linked this dietary pattern to an elevated risk of death from CVD, from cancer, and from all causes combined. ${ }^{23}$

\section{Example \#5: The Dietary Approaches to Stop Hypertension (DASH) Diet}

The DASH diet has a generous intake of fruit, vegetables, whole grain foods, nuts, and low-fat dairy products, combined with a reduced intake of meat. It therefore has many differences from a typical American diet, including a higher content of phytochemicals and fiber but a lower content of saturated fat. This diet was developed as a treatment for hypertension and has proven effective for that condition. ${ }^{24,25}$ This dietary treatment therefore represents the application of food synergy to actual clinical practice. 


\section{FOOD SYNERGY: EVIDENCE IN SUPPORT OF THE CONCEPT}

Food synergy is defined as additive or more than additive influences of dietary patterns, foods and food constituents on health. The composite nature of food, serving the life of the organism being eaten as well as the life of the eater, is central to the food synergy concept. Although prospective observational studies of nutrients suggested that some nutrients may help to prevent chronic disease, both RCTs and observational studies of isolated supplements have not found benefit. ${ }^{4,7,26}$ Thus, in these and many other examples, isolated nutrients do not appear to protect against disease although the foods from which they come may well do so, consistent with the food synergy concept. Viability of the food synergy idea implies 1) orchestrated balance in the biochemical constituents of the organism being eaten, 2) that the pieces of this orchestration survive digestion to arrive in body cells, i.e., platelets and 3) that the coordinated constituents mutually affect human biology. As described previously, ${ }^{5}$ all of these conditions exist in food as grown. For example, many biologic systems are in homeostasis (such as glucose and magnesium in humans). Plants must protect themselves against pests, often using polyphenolic pesticide compounds, yet must protect themselves against self-damage from these same compounds (e.g., by signalling or antidote compounds). In a specific example, coffee phenolics were found one hour after consumption in both low-density lipoproteins and platelets in roughly the same proportions as they exist in the consumed coffee; the combination of phenolics was observed to be biologically active. We have previously provided several examples in which whole foods have greater biological effects than did their individual components ${ }^{4}$. A recent example of this phenomenon in an animal model is prevention of tumorigenesis in mice using dietary walnuts. ${ }^{27}$

The food synergy construct makes several assertions. 1) Food and diet act on health and disease using highly specific, nonrandom, orchestrated mixtures. This argument is particularly pertinent for the major prevalent population health issues, including obesity, CVD, type 2 diabetes, and cancer, which are affected by multiple pathways and linked to syndromes. Alternative nutritional perspectives may be more appropriate in clinical nutrition. 2) These food effects are the fundamental unit, more fundamental than their constituent(s). Such individual constituents would be biologically active, but are not relevant to human health except in the artificial situation in which they are consumed in a drug-like way as supplements, which is a relatively recent situation and should be investigated separately from food.

3 ) The way food and diet pattern work has added complexity because of the 
existence of varietals and changes in pattern, but this additional complexity does not invalidate the fundamental nature of the action of food and diet pattern on health (it merely makes the problem more complex). 4) Understanding of the action of individual constituents must be in conformity with how these constituents work in concert when eaten as foods, but when viewed from the perspective of food as the fundamental unit, is actually of less interest than is food and diet pattern research. 5) Whether there is actual mathematical synergy, definable by product terms in explanatory models as more or less than additive, more or less than multiplicative, or more or less than is expected by any metric or computational algorithm, seems to be rather irrelevant. It appears that with thousands of ingredients entering a body together, with various bioavailabilities and half-lives, there well might be or even must be some major or minor interaction. However, the word synergy is justified to indicate the great complexity of evolutionarily selected mixtures of compounds consumed together and acting together (in the sense of all at the same time, whether mathematically synergistically or not), and as far as we know, needing each other to act as food.

\section{FOOD SYNERGY: IMPLICATIONS FOR RESEARCH}

Available methodologies for investigating diet-disease relationships all have significant limitations. As a result attempts to identify the specific substances in foods that are responsible for the particular health effects of foods often generate false conclusions for dietary advice. To focus on food, while not directly addressing physiological or biochemical pathways, does lead to conclusions that are valid for food as eaten and therefore for the particular mixtures of constituents that are contained in food. For those who are most interested in mechanistic answers, food-based research outcomes serve as the essential starting point for evaluation of individual constituents, singly or in combination. This may also work in reverse: knowledge of the physiological and biochemical functions of individual nutrients provides plausible explanations and/or hypotheses to be tested for food-based studies.

Observational epidemiology and its experimental variant RCTs are the only methods for investigating the effects of diet eaten over long periods in intact human beings; these methods should therefore be emphasized in any effort to understand nutrition. The basic sciences and mechanistic research investigate partial disease pathways in a variety of ways, using, for example, in vitro study of cells, clinical trials of foods and substances in animal models, genetic knockouts, and acute or short-term studies in humans. All 
methods have a place in the nutrition research agenda because convergent evidence from multiple research approaches makes for the most secure research inferences. Yet each method has strengths and weaknesses. Of particular note is that the RCT method, regarded in many ways as the gold standard for inference, has very different characteristics when the object of study is a drug or isolated substance than when the object of study is a food. A drug can be "simply and definitively" tested by recruiting a few thousand people and giving a drug vs. a placebo in a randomized, double-blind fashion for several years. This research relies on the mathematical model to make inferences about efficacy of the drug from the differential count of incident clinical events between the drug and placebo groups. The RCT method applied to foods is very difficult to carry out and often leads to ambiguous answers. Thus, inference about nutrition is a challenge that must cleverly combine evidence from observational epidemiologic cohort studies, well-designed RCTs, and supporting information from mechanistic studies. This position is expanded in the following sections with specific reference to research designs provided through observational studies, RCTs, and mechanistic research.

\section{OBSERVATIONAL EPIDEMIOLOGY: GOOD, BUT NOT EQUALLY APPROPRIATE FOR ALL PURPOSES}

Bradford Hill ${ }^{28}$ wrote a set of principles for making causal inferences based on observational data. Among these principles is temporality, that the presumed cause should precede the presumed effect. For this reason, crosssectional observational studies are often hard to interpret; longitudinal cohort studies are therefore preferred, with diet assessed at baseline and clinical events tallied after a period of time. However, a longitudinal design does not solve a major challenge in observational epidemiological research: confounding. We see this clearly with factors related to lifestyle, such as smoking, exercise, and body weight; these are not distributed randomly across the population but instead tend to be associated with each other. Intakes of different foods are correlated with each other, with the result that nutritional effects of one food may confound those of another, in line with the food synergy concept. Analysis of dietary patterns may get around confounding of foods with other foods by including a wide range of foods in the pattern. Confounding is avoided under the assumption that weighting of foods within the dietary pattern is appropriate. A partial solution to confounding of foods with foods may be to examine the relation of a food group with disease, adjusting for an informative dietary pattern. Another 
interesting conjecture is that residual confounding is likely to differ across studies; consistent findings across several longitudinal observational epidemiologic studies, as is the case for Mediterranean-type diet patterns, increasing our confidence in the observed relationships.

However, the problems created by confounding become more acute for study of isolated substances present in foods, for example the abundant chemicals in fruit, vegetables, and other plant foods. Such substances include folate, vitamin $\mathrm{C}$, potassium, fiber, and, of course, a great many phytochemicals, few of which have been carefully studied. One possible fix is to study the nutrient or substance of interest within multiple food groups, looking for consistency of findings, under the principle that an isolated substance effect should be apparent no matter what food (or supplement) that substance comes from..$^{29,30}$ This method was applied to dietary phosphorous $^{31}$; dietary phosphorous from dairy foods, but not from other foods, predicted incident hypertension. This may reflect food synergy. However, it could also reflect new confounding introduced by the confounders of dairy vs. non-dairy food. Another possible explanation is differential precision of dietary report for these two food groups. The same problem is seen with cereal fiber. Whole grain cereal foods provide many substances in addition to fiber. The importance of this is illustrated by the following example. Jacobs and colleagues observed that dietary fiber from whole grain cereals has a stronger protective association with disease than does the same amount of fiber from refined cereals. ${ }^{32}$ Phytochemicals present in whole grains are the likely explanation for this finding. This implies that we still have little clear idea of the importance of fiber in protection against disease beyond its direct effects in the colon. It is likely that phytochemicals in grain, as well as its fiber are important for health. The simple interpretation, and the most relevant for dietary advice, is that whole grain foods are nutritionally beneficial.

The general result is that when we compare different types of epidemiological studies, the ones that are easiest to interpret are those of dietary patterns; those of foods may be interpretable with additional care, but attempts to focus on single substances are generally dogged by confounding and unmodeled complexity due to the presence of many other substances. Consequently, the epidemiological method, while being an immensely valuable tool, has limited power to identify which nutrients or other bioactive substances in foods are likely to be responsible for particular health benefits. The method must therefore be used very carefully. 


\section{CLINICAL TRIALS: DESIGN CHALLENGES FOR FOOD-BASED STUDIES}

Despite the limitations of epidemiology, researchers have often shown much confidence in the findings of epidemiologic studies that have apparently identified single substances with potent disease-preventing action. This has provided the rationale for moving to the next stage and carrying out RCTs on the effects of single substances.

The RCT is a research tool of great value. The problem of confounding in the baseline measurements is solved by applying the RCT design. However, RCTs are expensive to carry out and can require several years and large sample sizes when disease incidence is the outcome. Alternatively, biomarkers of disease risk are studied with smaller sample size over weeks or months, but for this purpose we require an appropriate array of valid risk markers, the levels of which can be altered by the study treatment during the period of study. For these reasons it is logical to carry out large RCTs on purified dietary substances only when the supporting evidence is clear and strong.

Table 1

Comparison of design aspects of the randomized clinical trial design of the observational cohort design

\begin{tabular}{l|l|l}
\hline \multicolumn{1}{c|}{ Design Criterion } & \multicolumn{1}{|c}{ Clinical trial } & \multicolumn{1}{c}{ Observational Cohort } \\
\hline $\begin{array}{l}\text { Randomization/ } \\
\text { Comparison/ Internal } \\
\text { Validity }\end{array}$ & Excellent & Good \\
\hline Representation & $\begin{array}{l}\text { Restricted to eligibles } \\
\text { treatment considered } \\
\text { safe) }\end{array}$ & Comprehensive \\
\hline Realism & $\begin{array}{l}\text { Stylized treatment } \\
\text { delivery }\end{array}$ & Naturalistic treatment delivery \\
\hline Exposure period & Short (weeks or years) & $\begin{array}{l}\text { Long (e.g., whole prior life, adult life, } \\
\text { since onset of condition) }\end{array}$ \\
\hline $\begin{array}{l}\text { Confounding by } \\
\text { baseline characteristics }\end{array}$ & $\begin{array}{l}\text { Controlled } \\
\text { probabilistically }\end{array}$ & $\begin{array}{l}\text { Residual confounding always possible; } \\
\text { reduced when many studies in many } \\
\text { settings concur }\end{array}$ \\
\hline $\begin{array}{l}\text { Confounding by } \\
\text { changes during study }\end{array}$ & $\begin{array}{l}\text { A problem during study } \\
\text { period }\end{array}$ & $\begin{array}{l}\text { A problem before and during study } \\
\text { period }\end{array}$ \\
\hline $\begin{array}{l}\text { Level of investigator } \\
\text { control }\end{array}$ & High & $\begin{array}{l}\text { Low (but clever design and procedures } \\
\text { can help) }\end{array}$ \\
\hline
\end{tabular}


There are some similarities between RCTs and observational studies. The case that the RCT is a gold standard for inference is equivocal. Designs have different strengths ${ }^{33}$; the "three Rs of design" are randomization (internal validity), representation (fidelity to the applicable population), and realism (fidelity to how a treatment is really used). The basis for saying that the RCT is the gold standard for inference is its strength in the internal validity of the comparison between treatment and control (Table 1). The other two "Rs" relate to real life and are stronger in the observational setting, in which treatment is delivered comprehensively and naturalistically. The RCT is the clear preference in controlling confounding by baseline characteristics. But for other differences between RCTs and observational studies there are pros and cons for both designs, including exposure period (in many cases this seems to effectively pertain to most of a lifetime in the observational cohort study), confounding by changes during the study period (features that are correlated with treatment may be mislabeled as treatment effects), and level of investigator control.

Table 2

Comparison of design aspects in the randomized clinical trial design between drugs and food as the object of study

\begin{tabular}{l|l|l}
\hline Design Criterion & \multicolumn{1}{|c}{ Drug } & \multicolumn{1}{c}{ Food } \\
\hline Randomization & Easy & Possible, but hard to maintain long term \\
\hline Double blind & Easy, side effects? & Food is hard to mask \\
\hline Compliance & Easy, side effects? & $\begin{array}{l}\text { Major effect on life, several times a day, taste } \\
\text { and convenience big issues }\end{array}$ \\
\hline Feasibility & $\begin{array}{l}\text { A treatment can } \\
\text { always be formulated }\end{array}$ & $\begin{array}{l}\text { It may be difficult to accumulate sufficient } \\
\text { information for rarely eaten foods }\end{array}$ \\
\hline Duration & $\begin{array}{l}\text { Long term expensive, } \\
\text { possible }\end{array}$ & $\begin{array}{l}\text { Mostly weeks, long term expensive, com- } \\
\text { promised by compliance }\end{array}$ \\
\hline Specificity & $\begin{array}{l}\text { Single compound or } \\
\text { simple combination }\end{array}$ & $\begin{array}{l}\text { Food is average over time: varietals, growing } \\
\text { conditions, various preparations, food groups of } \\
\text { similar foods, non-organisms considered to be } \\
\text { food (salt, emulsifiers) }\end{array}$ \\
\hline Outcome & Clinical events & $\begin{array}{l}\text { Mostly intermediate outcomes, relevance to } \\
\text { clinical events may be questionable (multiple } \\
\text { pathways possible) }\end{array}$ \\
\hline Reference & Placebo or other drug & $\begin{array}{l}\text { "Infinite" possibilities for energy-bearing food, } \\
\text { e.g., Sat Fat } v s . \text { Poly Fat or } v s . \text { CHO }\end{array}$ \\
\hline
\end{tabular}


As 'treatment' studies, food-based RCTs share a design legacy with drug trials. However, many of the RCT design characteristics are different between drugs and food (Table 2). Compliance with random treatment assignment in a drug trial is easy, it is possible but hard to maintain with food. Double blind is easy with drugs, but is extremely difficult with foods. Compliance is in most cases easier to attain with drugs; food has a major effect on life several times a day; and taste and convenience are big issues during the observation. This tends to limit RCTs of food to a relatively short duration. For example, requiring a group of subjects who consume meat every day to become vegetarians for several years is obviously not an easy task. Such studies may be feasible; for example, excellent compliance was achieved when subjects with elevated blood pressure were asked to consume the DASH diet for four months. ${ }^{34}$ However, only partial success was achieved in the Women's Health Initiative where healthy women were required to make major changes in their diets and maintain them for six years. The investigators aimed to reduce total fat intake to 20 percent of calories, ${ }^{35,36}$ while the actual change was only about half of this.

Specificity of treatment in a sense favors study of drugs, but in another sense is not even applicable to the study of foods. A treatment may always be formulated for a RCT, but it may be difficult to accumulate sufficient information for rarely eaten foods in an observational epidemiologic study. Averages of food intakes may change over a long period of time. Food composition can also change; for example, apples can vary across varietals and growing conditions. The outcome could be clinical events in both the case of drugs and food as the object of study, but food trials tend to have intermediate outcomes, such as biochemical changes, given feasible duration. The relevance of these intermediate outcomes to clinical events creates particular challenges because there are always multiple pathways to clinical events.

Finally, the object of study is well specified in the case of drugs, but this requires considerable thought in the study of food. One might say that with energy-containing food there are actually an infinite number of dietary reference conditions. Any food can replace any other food on an isocaloric basis. Nevertheless, it seems to matter quite a lot whether saturated fat is replaced with polyunsaturated fat (reduced risk of $\mathrm{CHD}$ ) or refined carbohydrates (no change in disease rate). ${ }^{37-39}$ The same is true for nonenergy bearing food: significant substances could be replaced in the context of foods, which may require further consideration. 


\section{FROM OBSERVATIONAL STUDIES TO CLINICAL TRIALS: NOT THE RESULTS EXPECTED}

As mentioned above observational epidemiological research has limited power to identify which nutrients or other bioactive substances in foods are likely to be responsible for particular health benefits. In particular, such research can easily generate misleading inferences. Unfortunately, a number of RCTs have been carried out which have failed to appreciate these principles and have therefore been doomed from the start. A compelling example is provided by the story of trials involving nutrients with known antioxidant activity. A key finding that launched the saga was a report that $\beta$-carotene (derived as a weighted average of foods containing $\beta$-carotene) is inversely related to risk of lung cancer. ${ }^{40}$ Subsequent epidemiological studies during the 1980s extended these apparently exciting findings to several other types of cancer. ${ }^{41}$ From there it was only a small step to the belief that $\beta$-carotene may prevent several different forms of cancer.

$\beta$-Carotene was only one aspect of a broader investigation into vitamins with antioxidant properties. Epidemiological evidence indicated that vitamins $\mathrm{C}$ and $\mathrm{E}$ are also protective against disease. In the case of vitamin $\mathrm{C}$ numerous studies found that it has a negative association with risk of a range of cancers. ${ }^{42}$ Likewise, several cohort studies observed that intake of vitamin $\mathrm{E}$ displays a modest protective association with risk of CHD. ${ }^{16,43}$ This epidemiological evidence (combined with the results of mechanistic studies that are discussed below) was deemed sufficiently strong to justify carrying out RCTs. All three antioxidant vitamins were administered in a purified form at doses typically several times higher than the recommended daily allowance (RDA).

By the mid-1990s the findings from long-term RCTs on B-carotene started to appear and these consistently demonstrated that supplements of the nutrient do not prevent cancer. ${ }^{44}$ Much the same was seen for supplements of vitamin E, which has, at best, minimal value for the prevention of CHD. ${ }^{16}$ An especially significant finding was that supplements of all three antioxidants were actually adverse: total mortality was about five to six percent higher in subjects given the supplements. ${ }^{45,46}$

How can these negative results from RCTs be reconciled with the encouraging findings from epidemiological studies? The most plausible explanation is that the apparently protective associations seen in epidemiological studies results from phytochemicals and other substances that co-occur with antioxidant vitamins in the same foods. But we can go further: it seems highly likely that the disease-preventing actions of foods 
rich in antioxidants are a manifestation of food synergy. Hollman, et al. ${ }^{47}$ concluded that direct antioxidant action was an unlikely explanation for beneficial cardiovascular effects of polyphenol-rich foods and recommended that many other aspects of possible protection from polyphenols be investigated.

\section{BENCH SCIENCE: INCOMPLETE EXPLANATIONS FOR THE EFFECTS OF FOODS ON HEALTH}

A vast amount of research is carried out that investigates the functioning of the body and of the mechanisms that lead to disease. This research enterprise includes much research on how substances in food interact in the body and thereby may play a role in preventing or causing disease. On the surface this seems like an attractive alternative strategy to epidemiology for identifying which substances in food are responsible for health effects. Certainly, this strategy has revealed a great deal about the role played in the body by vitamins, minerals, amino acids, and other substances, and why deficiencies of them lead to specific symptoms. It is also true that the discovery of several important new drugs has grown out of an understanding of metabolic processes and cell physiology, such as cell receptors. There are a wide variety of findings that set an important backdrop for thinking about nutrition. For example, genotoxic and preneoplastic changes were seen in rats fed repeatedly heated coconut oil compared to the singly heated oil ${ }^{48}$; the repeatedly heated oil contained polycyclic aromatic hydrocarbons, which have been reported to have carcinogenic potential. These effects of repeatedly heating coconut oil are sufficient to raise a strong level of suspicion that any repeatedly heated oil is harmful. Another example is a pillar in the evidence that food synergy exists by showing that multiple substances in coffee were found conjugated, but otherwise in similar amounts in low density lipoprotein (LDL) cholesterol and platelets ${ }^{49,50}$ an hour after coffee consumption; and that these substances had biological effects (the LDL cholesterol was less oxidizable and the platelets were less aggregable after the coffee is consumed).

A tenet of the basic science approach is that it should, in theory, be possible to determine which phytochemicals are potentially chemopreventive or risk reducing by studying how each one interacts with the pathways of carcinogenesis or the processes of atherosclerosis. Given such basic science studies, the next step in each of these cases would be to carry out RCTs on relevant substances. 
But serious limitations exist in translating knowledge of single mechanisms to that of whole food intakes and dietary patterns, as has been argued previously. ${ }^{51-53}$ Two of the antioxidant vitamins discussed earlier provide excellent demonstrations of this. Following the publication of studies reporting that $\beta$-carotene may help prevent cancer, many studies were conducted during the 1980s that looked at the effects of the nutrient on body systems possibly related to cancer. This included studies of antioxidant action ${ }^{54}$ and immune function. ${ }^{55,56}$ That these studies lacked a solid rationale is demonstrated by the findings from RCTs (that appeared some years later) showing that supplemental B-carotene does not prevent human cancer. In the case of vitamin $\mathrm{E}$, researchers investigated the ability of vitamin $\mathrm{E}$ to retard the oxidation of LDL as this is thought to be a key step in the development of atherosclerosis. ${ }^{57}$ But as supplements of vitamin $\mathrm{E}$ do little or nothing to prevent $\mathrm{CHD}$, the synthesis of the mechanistic research that supported the RCTs of vitamin E appear to have drawn a wrong conclusion.

In recent years an enormous effort has been invested in learning everything there is to learn about human DNA and genomic variations. A goal is to create a personalized genomic medicine that will revolutionize medicine. We see some progress in gene work. However, we are concerned at the amount of resource that is being devoted to this enterprise, with a surfeit of falsely negative findings (particularly in genome-wide association studies; GWAS) and that the work seriously underestimates the extent of biologic complexity. ${ }^{58,59}$

\section{COMBINING KNOWLEDGE ACROSS THE RESEARCH DISCI- PLINES: A COMPLEX SCENARIO}

Even when knowledge is integrated across clinical, population, and mechanistic domains, a focus on a single nutrient may not prove fruitful. A case in point is that provided by research on folic acid with reference to the metabolite homocysteine. The relationship between homocysteine and CHD provides important lessons regarding both the limitations of observational epidemiology as well as on putting an overreliance on biomarkers of disease provided by knowledge of mechanistic pathways. Several observational studies had revealed that blood homocysteine levels are correlated with risk of CHD and other cardiovascular diseases. ${ }^{60,61}$ This suggests that the blood level of homocysteine is a useful biomarker for CHD. As supplements of certain B vitamins (folic acid and vitamins B6 and B12) are effective at lowering the blood homocysteine level, it was 
hypothesized that this intervention would be protective against CHD. But when this was tested in RCTs, there was no reduction of CHD, ${ }^{62-64}$ even though homocysteine levels were reduced by the intervention. The lesson here is that the observational studies that attempted to explain the association between blood homocysteine levels and risk of CHD could not confirm a simple, critical, causal role for homocysteine.

Besides folate's role in reducing homocysteine, research has firmly established that supplementary folic acid (a form of folate) is protective against neural tube defects (NTD), a group of congenital disorders that include spina bifida.$^{65}$ The explanation for this benefit is that a low maternal intake of folate before and during pregnancy creates a deficiency condition in the fetus, effectively hindering the development of the central nervous system. As a result of this discovery folic acid must now be added to enriched grain products in the USA and Canada.

A very different situation has developed in the area of cancer. For several types of cancer it appears that supplemental folic acid might help prevent cancer at an early stage of the disease but accelerate it if given at a later stage.$^{66-69}$ These effects can be apparently modified by the presence of genetic variations. In a pooled analysis of two clinical trials of folic acid and vitamins B6 and B12, lung cancer and total mortality were both elevated several years after the end of treatment with the increase attributed to folic acid. ${ }^{70}$

These observations suggest that there are significant limitations in focusing on a single nutrient and that this may lead to an oversimplification of a complex metabolic scenario. Likewise, the research that indicated mechanisms of action was also a long way from the context of overall diet and overall health. A more integrated and broad-reaching view clearly appears to be required.

\section{CONCLUSION}

This paper has examined various research designs applicable to nutrition research. It finds flaws in over-reliance on findings about isolated substances, although this focus characterizes much of the way that nutrition research has often been carried out. We propose to heed lessons from failed RCTs of isolated substances and develop more reliable research strategies. The first stage is the generation of observational epidemiologic evidence. Findings are interpreted based on the food synergy concept; in particular, an acceptance that findings about foods and health, such as fruit, vegetables, and whole grain cereals in relation to cancer and CVD, are an important 
milestone in the research discovery process. Findings about food allow the formulation of reliable dietary advice. Further studies of single substances in food, including phytochemicals, can be undertaken but with the food findings being the first step before carrying out any mechanistic studies. Selected large and long-term RCTs can also be carried out when appropriate but with food or diet pattern as the treatment to be tested.

A food synergy perspective may be the important new injection into understanding the relationship between food, health, and disease. For that reason it is important to think food first in seeking answers to questions that address either etiologic questions or public health dietary advice ${ }^{4}$. It is not clear whether food synergy reflects a true mathematical synergistic relationship (i.e., the whole risk or benefit is greater than the sum of the parts) or else is simply an additive effect. At minimum, though, even in the absence of mathematical synergy, foods are complex mixtures, tested by evolution, which we would not come to by de novo constitution from individual constituents. By contrast, the alternative strategy, that of too much focus on the large number of individual substances in food, is generally much less productive in generating key information that provides a better understanding of how diet affects health. Investigation of the effects of isolated substances on disease should also be considered given their effects in their natural food setting. This approach to understanding isolated substances would also help to address the concept of food synergy.

Observational studies are required to identify which dietary patterns or foods appear to have the greatest impact on disease. Prospective epidemiological research is a reliable tool for that purpose, particularly when it is required that findings be replicated several times such that residual confounding is likely to vary between settings (and is therefore unlikely to explain the findings of any given study). For the most promising foods and patterns, in the next stage corresponding RCTs can be carried out. Throughout this process highly pertinent basic science research adds to the plausibility and relevance of the overall findings.

There are, however, serious challenges involved in the design and execution of RCTs. First, by far the most useful ones are long term. Second, blinding of subjects in different treatment groups as to what they are eating is difficult to accomplish; if this criterion is required, it may restrict the kinds of diets that can be studied. And, third, compliance with fixed diets may be an even larger problem. Because of the fundamental differences from drug-type RCTs, RCTs of food or diet pattern would need to redefine goals, make design concessions, and/or get a great deal of input from dietetics on how to design these studies - dietary modeling, dietary counseling, and dietary assessments are critical parts of an effective protocol. 
In support of public health dietary advice and given the practical circumstances of solving the complex problem of interacting food constituents, the food synergy concept implies that a change in nutrition research strategy is needed. This requires a focus on foods and dietary patterns, emphasizing large observational epidemiologic studies and judiciously chosen RCTs and basic science studies. Little progress will be made if most of the effort goes to the basic sciences and only a small fraction to research questions directly related to dietary effects. The concept of food synergy will enable a better balance in knowledge generation directly translatable to public health dietary advice.

\author{
Acronyms list: \\ $\mathrm{CHD}=$ Coronary heart disease \\ $\mathrm{CVD}=$ Cardiovascular disease \\ DASH $=$ Dietary Approaches to Stop Hypertension \\ LDL $=$ Low density lipoprotein \\ $\mathrm{RCT}=$ Randomized control trial \\ RDA $=$ Recommended daily allowance
}

Conflicts of Interest: Drs. Jacobs and Tapsell are unpaid members of the Scientific Advisory Board of the California Walnut Commission. In addition, Dr. Tapsell is a member of Danone Institute's Nutrition Prize Committee and of the Science Advisory Council of McCormick's Science Institute. There are no other potential conflicts of interest.

\title{
REFERENCES
}

1. Jacobs DR, Murtaugh MA. It's more than an apple a day: an appropriately processed plant-centered dietary pattern may be good for your health. Am J Clin Nutr. 2000;72:899-900.

2. Messina M, Lampe JW, Birt DF, Appel LJ, Pivonka E, Berry B, et al. Reductionism and the narrowing nutrition perspective: time for reevaluation and emphasis on food synergy. J Am Diet Assoc. 2001;101:1416-9.

3. Jacobs DR, Steffen LM. Nutrients, foods, and dietary patterns as exposures in research: a framework for food synergy. Am J Clin Nutr. 2003;78:508S-13S.

4. Jacobs DR Jr, Tapsell LC. Food, not nutrients, is the fundamental unit in nutrition. Nutr Rev. 2007;65:439-50.

5. Jacobs DR Jr, Gross MD, Tapsell LC. Food synergy: an operational concept for understanding nutrition. Am J Clin Nutr. 2009;89:1543S-8S.

6. Giovannucci E, Liu Y, Rimm EB, Hollis BW, Fuchs CS, Stampfer MJ, et al. Prospective study of predictors of vitamin D status and cancer incidence and mortality in men. J Natl Cancer Inst. 2006;98:451-9. 
7. Mursu J, Robien K, Harnack LJ, Park K, Jacobs DR. Dietary supplements and mortality in older women: the Iowa Women's Health Study. Arch Int Med 2011;171:1625-33.

8. Sacks FM, Svetkey LP, Vollmer WM, Appel LJ, Bray GA, Harsha D, et al. for the DASH-Sodium Collaborative Research Group. Effects on blood pressure of reduced dietary sodium and the Dietary Approaches to Stop Hypertension (DASH) diet. DASH-Sodium Collaborative Research Group. N Engl J Med. 2001;344:3-10.

9. He FJ, MacGregor GA. A comprehensive review on salt and health and current experience of worldwide salt reduction programmes. J Hum Hypertens. 2009;23:363-84.

10. Cook NR, Cutler JA, Obarzanek E, Buring JE, Rexrode KM, Kumanyika SK, et al. Long term effects of dietary sodium reduction on cardiovascular disease outcomes: observational follow-up of the trials of hypertension prevention (TOHP). BMJ. 2007;334:885-8.

11. World Cancer Research Fund/American Institute for Cancer Research. Food, nutrition, physical activity, and the prevention of cancer: a global perspective. Washington, DC: AICR; 2007.

12. Mozaffarian D, Katan MB, Ascherio A, Stampfer MJ, Willett WC. Trans fatty acids and cardiovascular disease. N Engl J Med. 2006;354:1601-13.

13. Mozaffarian D, Aro A, Willett WC. Health effects of trans-fatty acids: experimental and observational evidence. Eur J Clin Nutr. 2009;63:S5-S21.

14. Danaei G, Ding EL, Mozaffarian D, Taylor B, Rehm J, Murray CJ, et al. The preventable causes of death in the United States: comparative risk assessment of dietary, lifestyle, and metabolic risk factors. PLoS Med. 2009;6:e1000058.

15. Rimm E, Temple NJ. What are the health implications of alcohol consumption? In: Temple N, Wilson T, Jacobs DR, editors. Nutritional health: strategies for disease prevention. Totowa, New Jersey: Humana Press; 2006. p.211-21.

16. Mente A, de Koning L, Shannon HS, Anand SS. A systematic review of the evidence supporting a causal link between dietary factors and coronary heart disease. Arch Intern Med. 2009;169:659-69.

17. McCullough ML, Feskanich D, Stampfer MJ, Giovannucci EL, Rimm EB, Hu $\mathrm{FB}$, et al. Diet quality and major chronic disease risk in men and women: moving toward improved dietary guidance. Am J Clin Nutr. 2002;76:1261-71.

18. van Dam RM, Li T, Spiegelman D, Franco OH, Hu FB Combined impact of lifestyle factors on mortality: prospective cohort study in US women. BMJ. 2008;337:a1440.

19. Lockheart MS, Steffen LM, Rebnord HM, Fimreite RL, Ringstad J, Thelle DS, et al. Dietary patterns, food groups and myocardial infarction: A case-control study. Br J Nutr. 2007;98:380-7.

20. Nettleton JA, Schulze MB, Jiang R, Jenny NS, Burke GL, Jacobs DR. A prioridefined dietary patterns and markers of cardiovascular disease risk in the multiethnic study of atherosclerosis (MESA). Am J Clin Nutr. 2008;88:185-94. 
21. Nettleton JA, Steffen LM, Ni H, Liu K, Jacobs DR Jr. Dietary patterns and risk of incident type 2 diabetes in the Multi-Ethnic Study of Atherosclerosis (MESA). Diabetes Care. 2008;31:1777-82.

22. Jacobs DR, Sluik D, Rokling-Andersen MH, Anderssen SA, Drevon CA. Association of 1-y changes in diet pattern with cardiovascular disease risk factors and adipokines: results from the 1-y randomized Oslo Diet and Exercise Study. Am J Clin Nutr. 2009;89:509-17.

23. Heidemann C, Schulze MB, Franco OH, van Dam RM, Mantzoros CS, Hu FB. Dietary patterns and risk of mortality from cardiovascular disease, cancer, and all causes in a prospective cohort of women. Circulation. 2008;118:230-7.

24. Appel LJ, Moore TJ, Obarzanek E, et al:Aclinical trial of the effects of dietary patterns on blood pressure. DASH Collaborative Research Group. N Engl J Med. 1997;336:1117-1124.

25. Svetkey LP, Simons-Morton D, Vollmer WM, Appel LJ, Conlin PR, Ryan DH, et al. Effects of dietary patterns on blood pressure: subgroup analysis of the Dietary Approaches to Stop Hypertension (DASH) randomized clinical trial. Arch Intern Med. 1999;159:285-93.

26. Park SY, Murphy SP, Wilkens LR, Henderson BE, Kolonel LN. Multivitamin use and the risk of mortality and cancer incidence: the multiethnic cohort study. Am J Epidemiol. 2011;173:906-14.

27. Hardman WE, Ion G, Akinsete JA, Witte TR. Dietary walnut suppressed mammary gland tumorigenesis in the C(3)1 TAg mouse. Nutr Cancer. 2011;63:960-70.

28. Hill AB. The environment and disease: association or causation? Proc R Soc Med. 1965;58:295-300.

29. Willett W. Nutritional Epidemiology. New York: Oxford University Press, 1998.

30. Jacobs DR. Challenges in research in nutritional epidemiology. In: Temple NJ, Wilson T, Jacobs DR, editors. Nutritional health: strategies for disease prevention. 2nd ed. Totowa, NJ: Humana Press; 2006. p.25-35.

31. Alonso A, Nettleton JA, Ix JH, de Boer IH, Folsom AR, Bidulescu A, Kestenbaum BR, Chambless LE, Jacobs DR Jr. Dietary phosphorus, blood pressure, and incidence of hypertension in the atherosclerosis risk in communities study and the multi-ethnic study of atherosclerosis. Hypertension. 2010;55:776-84.

32. Jacobs DR, Pereira MA, Meyer KA, Kushi LH. Fiber from whole grains, but not refined grains, is inversely associated with all-cause mortality in older women: the Iowa women`s health study. J Am Coll Nutr. 2000;19:326S-30S.

33. Kish L. Statistical Design for Research. Hoboken, NJ: (Wiley Classics Library) Wiley; 2004.

34. Blumenthal JA, Babyak MA, Hinderliter A, Watkins LL, Craighead L, Lin PH, et al. Effects of the DASH diet alone and in combination with exercise and weight loss on blood pressure and cardiovascular biomarkers in men and women with high blood pressure: the ENCORE study. Arch Intern Med. 2010;170:126-35. 
35. Howard BV, Van Horn L, Hsia J, Manson JE, Stefanick ML, WassertheilSmoller S, et al. Low-fat dietary pattern and risk of cardiovascular disease: the Women's Health Initiative Randomized Controlled Dietary Modification Trial. JAMA. 2006;295:655-66.

36. Carty CL, Kooperberg C, Neuhouser ML, Tinker L, Howard B, WactawskiWende J, et al. Low-fat dietary pattern and change in body-composition traits in the Women's Health Initiative Dietary Modification Trial. Am J Clin Nutr. 2011;93:516-24.

37. Mozaffarian D, Micha R, Wallace S. Effects on coronary heart disease of increasing polyunsaturated fat in place of saturated fat: a systematic review and meta-analysis of randomized controlled trials. PLoS Med 2010;7:e1000252.

38. Jakobsen MU, Dethlefsen C, Joensen AM, Stegger J, Tjønneland A, Schmidt EB, Overvad K. Intake of carbohydrates compared with intake of saturated fatty acids and risk of myocardial infarction: importance of the glycemic index. Am J Clin Nutr. 2010; 91:1764-8.

39. Kromhout D, Geleijnse JM, Menotti A, Jacobs DR. The confusion about dietary fatty acids recommendations for CHD prevention. Brit J Nutr. 2011;106:62732.

40. Shekelle RB, Lepper M, Liu S, Maliza C, Raynor WJ Jr, Rossof AH, et al. Dietary vitamin A and risk of cancer in the Western Electric study. Lancet. 1981;2:1185-90.

41. Temple NJ, Basu TK. Role of beta-carotene in the prevention of cancer - a review. Nutrition Res. 1988;8:685-701.

42. Block G. Vitamin C status and cancer. Epidemiologic evidence of reduced risk. Ann N Y Acad Sci. 1992;669:280-90.

43. Knekt P, Ritz J, Pereira MA, O'Reilly EJ, Augustsson K, Fraser GE, et al. Antioxidant vitamins and coronary heart disease risk: a pooled analysis of 9 cohorts. Am J Clin Nutr. 2004;80:1508-20.

44. Druesne-Pecollo N, Latino-Martel P, Norat T, Barrandon E, Bertrais S, Galan P, et al. Beta-carotene supplementation and cancer risk: a systematic review and metaanalysis of randomized controlled trials. Int J Cancer. 2010;127:172-84.

45. Bjelakovic G, Nikolova D, Gluud LL, Simonetti RG, Gluud C. Mortality in randomized trials of antioxidant supplements for primary and secondary prevention: systematic review and meta-analysis. JAMA. 2007;297:842-57.

46. Bjelakovic G, Nikolova D, Gluud LL, Simonetti RG, Gluud C. Antioxidant supplements for prevention of mortality in healthy participants and patients with various diseases. Cochrane Database Syst Rev. 2008;CD007176.

47. Hollman PC, Cassidy A, Comte B, Heinonen M, Richelle M, Richling E, et al. The biological relevance of direct antioxidant effects of polyphenols for cardiovascular health in humans is not established. J Nutr. 2011;141: 989S-1009S. 
48. Srivastava S, Singh M, George J, Bhui K, Murari Saxena A, Shukla Y. Genotoxic and carcinogenic risks associated with the dietary consumption of repeatedly heated coconut oil. Br J Nutr. 2010;104:1343-52.

49. Natella F, Nardini M, Belelli F, Scaccini C. Coffee drinking induces incorporation of phenolic acids into LDL and increases the resistance of LDL to ex vivo oxidation in humans. Am J Clin Nutr 2007;86:604-9.

50. Natella F, Nardini M, Belelli F, Pignatelli P, Di Santo S, Ghiselli A, et al. Effect of coffee drinking on platelets: inhibition of aggregation and phenols incorporation. Br J Nutr. 2008;100:1276-82.

51. Roberts S, Temple NJ. Medical research: a bettor's guide. Am J Prev Med. 2002;23:231-2.

52. Temple NJ. Medical research: a complex problem. In: Temple NJ, Burkitt DB, editors. Western diseases: their dietary prevention and reversibility. Totowa, New Jersey: Humana Press; 1994. p.419-36.

53. Temple NJ. Nutrition and disease: challenges of research design. Nutrition. 2002;18:343-7.

54. Burton GW, Ingold KU. beta-Carotene: an unusual type of lipid antioxidant. Science. 1984;224:569-73.

55. Schwartz J, Suda D, Light G. Beta carotene is associated with the regression of hamster buccal pouch carcinoma and the induction of tumor necrosis factor in macrophages. Biochem Biophys Res Commun. 1986;136:1130-5.

56. Rhodes J. Human interferon action: reciprocal regulation by retinoic acid and beta-carotene. J Natl Cancer Inst. 1983;70:833-7.

57. Asmis R, Llorente VC, Gey KF. Prevention of cholesteryl ester accumulation in P388D1 macrophage-like cells by increased cellular vitamin E depends on species of extracellular cholesterol. Conventional heterologous non-human cell cultures are poor models of human atherosclerotic foam cell formation. Eur J Biochem. 1995;233:171-8.

58. Temple NJ, Thompson A, editors. Excessive medical spending: facing the challenge. Oxford: Radcliffe Publishing; 2007.

59. McGuire AL, Cho MK, McGuire SE, Caulfield T. The future of personal genomics. Science. 2007;317:1687.

60. Seshadri N, Robinson K. Homocysteine, B vitamins, and coronary artery disease. Med Clin North Am. 2000;84:215-37.

61. Stubbs PJ, Al-Obaidi MK, Conroy RM, Collinson PO, Graham IM, Noble IM. Effect of plasma homocysteine concentration on early and late events in patients with acute coronary syndromes. Circulation. 2000;102:605-10.

62. Bazzano LA, Reynolds K, Holder KN, He J. Effect of folic acid supplementation on risk of cardiovascular diseases: a meta-analysis of randomized controlled trials. JAMA. 2006;296:2720-6.

63. Albert CM, Cook NR, Gaziano JM, Zaharris E, MacFadyen J, Danielson E. Effect of folic acid and B vitamins on risk of cardiovascular events and total mortality among women at high risk for cardiovascular disease: a randomized trial. JAMA. 2008;299:2027-36. 
64. Study of the Effectiveness of Additional Reductions in Cholesterol and Homocysteine (SEARCH) Collaborative Group, Armitage JM, Bowman L, Clarke RJ, Wallendszus K, Bulbulia R, Rahimi K, et al. Effects of homocysteine-lowering with folic acid plus vitamin B12 vs placebo on mortality and major morbidity in myocardial infarction survivors: a randomized trial. JAMA. 2010;303:2486-94.

65. Wolff T, Witkop CT, Miller T, Syed SB; U.S. Preventive Services Task Force. Folic acid supplementation for the prevention of neural tube defects: an update of the evidence for the U.S. Preventive Services Task Force. Ann Intern Med. 2009;150:632-29.

66. Hubner RA, Houlston RS. Folate and colorectal cancer prevention. Br J Cancer. 2009;100:233-9.

67. Mason JB. Folate, cancer risk, and the Greek god, Proteus: a tale of two chameleons. Nutr Rev. 2009;67:206-12.

68. Figueiredo JC, Grau MV, Haile RW, Sandler RS, Summers RW, Bresalier RS, et al. Folic acid and risk of prostate cancer: results from a randomized clinical trial. J Natl Cancer Inst. 2009;101:432-5.

69. Stolzenberf-Solomon RZ, Chang SC, Leitzmann MF, Johnson KA, Johnson C, Buys SS, et al. Folate intake, alcohol use and postmenopausal breast cancer risk in the Prostate Lung Colorectal and Ovarian Screening Trial. Am J Clin Nutr. 2006;83:895-904.

70. Ebbing M, Bønaa KH, Nygård O, Arnesen E, Ueland PM, Nordrehaug JE, et al. Cancer incidence and mortality after treatment with folic acid and vitamin B12. JAMA. 2009;302:2119-26 